\title{
A PINTURA ARTÍSTICA EM ESPAÇOS URBANOS TOMBADOS NO BRASIL: LIMITES E POSSIBILIDADES
}

\author{
Fabiana Santos Dantas \\ Universidade Federal de Pernambuco, Brasil
}

\begin{abstract}
Resumo
As cidades nascem para possibilitar a convivência das pessoas e o compartilhamento de sua vida cotidiana. Como habitat, são palcos para manifestações as mais variadas, inclusive artísticas, reveladas por suas formas arquitetônicas, pelos estilos de vida, e pela percepção e atitudes ambientais daqueles que nelas habitam. Algumas cidades tornam-se monumentos e frações do seu espaço, passam a ser regidas por normas especiais e diferenciadas, mais restritivas. O tombamento estabelece um regime diferenciado de exercício do direito de propriedade, com obrigações para proprietários e vizinhos, que o tornam um espaço de exceção. Neste artigo discute-se como compatibilizar as manifestações artísticas, em especial a pintura em imóveis tombados, com o objetivo de pontuar as principais questões e estabelecer delineamento legal das normas de preservação sobre a matéria. O resultado esperado é contribuir para uma melhor compreensão do tema através de um panorama e da contextualização da discussão, bem como de documentos legislativos e bibliografia pertinente, com foco na compreensão dos limites para a atuação da fiscalização pela Administração Pública brasileira na compatibilização entre a preservação de bens culturais e a efetivação da democracia e exercício de direitos culturais. A metodologia de pesquisa consistiu em pesquisa bibliográfica, realizada através da análise de livros, artigos científicos, de revista e pesquisa documental quanto à legislação específica.
\end{abstract}

\section{Palavras-chave}

Direito Ambiental; patrimônio cultural; preservação

\section{Artistic PAinting in PROTECTED URBAN PLACES IN BRAZIL: ITS LIMITS AND POSSIBILITIES}

\begin{abstract}
Cities exist to make possible human coexistence and daily life sharing. As habitat, cities are the setting for various manifestations, including artistic ones, revealed by their architectural forms, lifestyles, as well as by the perception and attitudes of those who inhabit them. Some cities become monuments and parts of their territories are governed by special, more restrictive laws. A protected historical building requires a different way of exercising property rights, with specific obligations for owners and neighbours, which makes it a unique place. This article is an attempt to understand artistic manifestations, especially paintings, in protected historical buildings, with the goal of highlighting the main issues and establishing a legal outline of preservation laws. The expected result is to contribute to a better understanding of the topic through a panorama and contextualization of the discussion, as well as legislative documents and relevant bibliography, focusing on the understanding of the performance limits of the supervision by the Brazilian Public Administration of the compatibility between the preservation of cultural assets, the realization of democracy, and the exercise of cultural rights. The research methodology consisted of
\end{abstract}


a literature search, through the analysis of books, scientific articles from magazines and peerreviewed journals, as well as documental research relative to specific legislation.

\section{palpite iograffiti}

Figura 1: "Sol-te"

Fonte: Leminski, 2013, p. 153

\section{INTRODUÇÃo}

O habitat humano possui, entre outros, um valor estético capaz de influir na qualidade de vida. Algumas cidades, em diferentes épocas e por diferentes motivos, adotaram estratégias de embelezamento através da construção de lugares públicos aprazíveis, como jardins e praças, do ordenamento, e por serviços públicos como o saneamento e a limpeza urbana.

O poder público também é um importante produtor e promotor da cultura, criando monumentos e investindo recursos na aquisição e exposição de obras de arte que ornamentam as cidades brasileiras. Em algumas delas há até mesmo leis que estabelecem a obrigação jurídica de prover áreas com obras de arte, como se pode ver no artigo 129 da Lei Municipal n 16.292/97 (Recife), que dispõe: "toda edificação, com área igual ou superior a $1.000 \mathrm{~m}^{2}$ (um mil metros quadrados), deverá conter, em lugar de destaque, obra de arte executada em escultura, pintura, mural ou relevo escultórico".

Normas administrativas de tal natureza implicam diversas reflexões interessantes, por exemplo, quanto à necessidade operacional de uma definição legal de obra de arte, quem define a adequação ou não da obra de arte submetida à apreciação do poder público, se há ou não juízos de qualidade sobre a obra, a possibilidade de utilizar réplicas e reproduções e, até mesmo quem é artista apto a executá-la'. A simples enunciação dessas questões aponta para uma possível inconstitucionalidade das normas que impõem esse tipo de obrigação ou, no mínimo, um vigoroso questionamento quanto à legalidade dos juízos que a administração pública faça sobre o valor artístico.

Além do poder público, a sociedade e o indivíduo também intervêm esteticamente nas cidades, pois viver nelas significa utilizar o espaço comum para o exercício de

\footnotetext{
' Observe-se que a Lei Municipal n $14.239 / 80$ (Recife) prevê que "somente poderão executar os serviços, de que trata este artigo os artistas plásticos pernambucanos ou radicados na Região Metropolitana do Recife, previamente inscritos na Empresa de Urbanização do Recife - URB".
} 
diversas liberdades, inclusive de manifestação artística, de variadas formas: nas ruas há dança, música, teatro, pintura, escultura, arquitetura, que dão a cada lugar o seu peculiar modo de existir.

A questão torna-se mais sensível quando se trata de manifestações artísticas materiais em espaços urbanos protegidos. Existem normas jurídicas que restringem ou proíbem determinadas formas de expressão visando a preservação de edificações ou conjuntos urbanos contra mutilações e descaracterizações, como ocorre com o instrumento do tombamento, mas não exclusivamente através dele.

O objetivo deste artigo é fazer uma breve reflexão sobre os limites e possibilidades das intervenções artísticas que têm áreas tombadas como suporte, a partir de uma breve análise sobre os instrumentos legais de preservação do meio ambiente cultural contrapondo o grafite e a pichação e ilustrando a aplicação das normas legais brasileiras por meio de ligeiro estudo de caso em que foi autorizada a realização de uma pintura artística em um imóvel tombado da cidade do Recife. Para tanto, realizou-se a análise da legislação aplicável, focando na discussão da gestão pública e dos critérios adotados para aprovar uma pintura artística ou classificá-la como ilícita, e na necessária compatibilização entre a preservação de bens culturais, a efetivação da democracia e exercício de direitos culturais, com apoio em pesquisa bibliográfica, realizada através da análise de livros, artigos científicos e de revistas.

\section{OS ESPAÇOS URBANOS PROTEGIDOS}

Os espaços urbanos podem ser protegidos por muralhas visíveis e invisíveis, criadas para delimitar um perímetro de controle mais direto e sistemático, com finalidades específicas, como a segurança e a proteção e promoção da estética urbana, ou genéricos como preservar uma certa visão de mundo ${ }^{2}$ materializada na cidade.

O habitat urbano é capaz de influir na saúde física e mental e inspirar sentimentos de afeição ou repulsa. O indivíduo desenvolve uma relação com o território, de caráter afetivo, por causa das utilidades que lhe proporciona (sustento, satisfação de necessidades), por questões estéticas, religiosas. Esses, dentre outros fatores, levam ao afeiçoamento do indivíduo pelo lugar como resultado das impressões sensoriais (tato, olfato, paladar, audição e visual) e existenciais em relação ao ambiente (Tuan, 1980).

A relação afetiva com um território é manifestada através de intervenções artísticas como a pintura, a literatura, a construção de monumentos intencionais ou não, vestígios materiais (por exemplo, edifícios, sambaquis, lixões) que podem ganhar valor cultural para preservação. Essas intervenções são fundamentais para moldar o ambiente às necessidades dos indivíduos e grupos, que atendidas suficientemente correspondem ao conceito de "qualidade de vida", e frequentemente são manifestadas na legislação como direitos.

\footnotetext{
${ }^{2} \mathrm{~A}$ importância cosmológica de uma cidade é inferida pela forma, orientação, estrutura hierárquica do espaço, tipos de arquitetura e da manifestação da organização social e das crenças da época (Tuan, 1980, p. 189). Entretanto, essa cosmovisão já não é mais tão concreta como antes no planejamento das cidades: a tradução da ordem social para o espaço não é autoevidente, e as cidades moldam-se e desenvolvem-se pela conveniência e por fatores econômicos.
} 
Dentre essas necessidades, a manutenção de uma estética aprazível transformou-se em um direito na legislação brasileira porque a paisagem pode produzir emoções benéficas ou ansiedade, medo, desprazer, com impacto na qualidade de vida das pessoas, entendida como o bem-estar físico e espiritual associado à dignidade humana (Sanches, 2009, p. 76), ao qual se refere o artigo 182 da Constituição Federal de 1988 ao tratar sobre política urbana3.

Para garantir esse bem-estar, a estética urbana é protegida contra a poluição através de diversos dispositivos legais ${ }^{4}$, podendo ser apontados exemplificativamente alguns elementos que comprometem a paisagem: excesso de publicidade, pichações, falta de conservação da fachada dos imóveis, falta de arborização, proliferação de antenas, fios, e postes de distribuição de energia, cabos telefônicos, porque tal acúmulo impede ou dificulta a percepção (Sanches, 2009, p. 83).

Existem vários instrumentos utilizados para a proteção e preservação material de espaços urbanos, principalmente em razão do regime de competências estabelecido na Constituição Federal para a criação de normas protetivas do patrimônio cultural e natural (legislativas) e para executá-las através de ações administrativas (competência material). Em relação à preservação do patrimônio cultural, o artigo 23 prevê a competência comum entre a União, Estados, Distrito Federal e Municípios, impondo a cooperação em razão da importância do tema para a coletividade.

Entretanto, não existe uma norma geral federal que sistematize a proteção estatal dos bens culturais, prevendo instrumentos, metodologias e procedimentos utilizados na preservação, o que acarreta a existência de normas jurídicas protetivas diversas, e consequentemente critérios e instrumentos diferentes, que podem não favorecer a atuação conjunta das entidades.

O principal instrumento de preservação de imóveis isolados e conjuntos no Brasil é o tombamento, instituído pelo Decreto-Lei $n^{\circ} 25 / 37$. Trata-se de um instrumento administrativo, portanto é manejado principalmente pelo poder executivo, mas há exemplos legislativos e judiciais, que consistem em estabelecer limitações aos poderes inerentes ao direito de propriedade (usar e dispor), através de obrigações de fazer (conservar o bem cultural tombado, notificar a autoridade em caso de roubo ou dano), e de não fazer (não realizar intervenções físicas sem a prévia autorização estatal). A finalidade desse instrumento é impedir que alterações físicas sem controle da administração descaracterizem o objeto material (imóvel isolado ou conjunto), prevenindo ameaças à sua existência, à integridade e à permanência dos seus valores para a coletividade e cuja conservação é de interesse público (Dantas, 2015, pp. 41-42).

Em áreas tombadas, qualquer intervenção artística que utilize suportes materiais, como a pintura ou escultura, depende da prévia autorização do poder público, sob pena

\footnotetext{
${ }^{3}$ Art. 182. "A política de desenvolvimento urbano, executada pelo poder público municipal, conforme diretrizes gerais fixadas em lei, tem por objetivo ordenar o pleno desenvolvimento das funções sociais da cidade e garantir o bem-estar de seus habitantes".

${ }^{4}$ Sanches (2009, p. 80) destaca diversos dispositivos legais que podem ser citados como exemplos de proteção da paisagem: artigo $3^{\circ}$, I e III da Lei ${ }^{\circ} 6938 / 81$; artigo $4^{\circ}$, VI da Lei $n^{\circ}$ 9985/2000, Lei ${ }^{\circ}$ 4737/65 (Código Eleitoral, artigo 243, VIII), Lei $n^{\circ} 8078 / 90$ (Código de defesa do consumidor) artigo 37, $\int 2^{\circ}$, lei 9605/98 e Lei $n^{\circ}$ 106257/2001 (Estatuto da Cidade), artigo 37 , VII.
} 
da configuração de ilícitos civil, penal e administrativo, como será visto no próximo item. Já para garantir a visibilidade e a ambiência do bem tombado, a legislação prevê a delimitação de uma área de proteção denominada "vizinhança" ou "entorno", onde também são estabelecidas certas limitações, por exemplo, quanto à distância, perspectiva e altura de edificações, bem como a proibição de afixar objetos.

Além do tombamento, existem outros instrumentos de preservação que limitam ou proíbem a execução de obras artísticas em bens imóveis e conjuntos para prevenir eventual descaracterização, entre os quais podem ser citadas certas formas de zoneamento urbano, com a criação de zonas do patrimônio que possuem limitações previstas no Plano Diretor (municipal), ou mesmo através de normas específicas para uma tipologia de bens culturais, como ocorre com a Lei $n^{\circ} 11483 / 2007$ (patrimônio ferroviário).

É certo que o poder público pode indicar a viabilidade ou inviabilidade da execução de uma obra de arte em determinado local, proibindo ou permitindo mediante certas condições. Mais difícil é definir se, como e quando, o poder público pode fazer juízos quanto ao valor artístico de determinadas obras, inclusive quanto a questões de moralidade, o que pode significar o exercício abusivo do poder da polícia administrativa e/ou censura.

\section{ÁREAS TOMBADAS VERSUS LIBERDADE DE MANIFESTAÇÃo ARTÍSTICA: GRAFITE E PICHAÇÃo}

Refletir sobre limites e possibilidades das intervenções artísticas em imóveis tombados, considerados como suportes, necessariamente significa considerar que uma política de preservação é uma forma de discurso sobre a cidade, e também estabelece uma forma de uso específico. A cidade vai adquirindo valores, significados e usos que vão sendo construídos e substituídos ao longo do tempo, e o desafio é garantir a permanência dos vestígios materiais para permitir diferentes leituras.

Então, indaga-se: como compatibilizar a proteção das estruturas tombadas como suportes de manifestações artísticas? Se, quando e como é possível permitir alterações nesses suportes sem configurar dano e crime? Qual é o limite da "autorização prévia" do poder público? Pode incidir apenas sobre a forma ou sobre o conteúdo da manifestação artística? Todas essas questões serão objeto de reflexão a partir da análise da legislação federal brasileira relativa à preservação do patrimônio cultural material, inferidas as respostas pela sua interpretação e segundo a práxis administrativa da entidade de preservação nacional, o Instituto do Patrimônio Histórico e Artístico Nacional (IPHAN) 5 .

\section{Pinturas ARTísticas EM ÁREAS TOMbadas}

O tombamento em nível federal é o instrumento que visa preservar a integridade física de bens materiais móveis e imóveis, mediante o estabelecimento de limitações

\footnotetext{
${ }_{5} \mathrm{O}$ Instituto do Patrimônio Histórico e Artístico Nacional (IPHAN) é a entidade governamental responsável pela seleção dos bens culturais móveis e imóveis, tangíveis e intangíveis, que compõem o patrimônio cultural nacional tutelado pelo Estado brasileiro e são objeto das políticas públicas de preservação.
} 
administrativas e de obrigações quanto ao que fazer e não fazer, que se encontra disciplinado pelo Decreto-lei $n^{\circ} 25 / 37$.

Ao tombar um bem imóvel, a administração pública pode considerá-lo de forma isolada ou conjunta, o qual gozará de um regime especial do exercício do direito de propriedade. O proprietário de um imóvel tombado tem obrigações diferenciadas, fundadas no princípio da função social da propriedade, e deve adotar em favor do seu imóvel medidas de conservação, e solicitar a autorização para eventuais intervenções. Observe-se o que dispõe o artigo 17 do Decreto-Lei n $25 / 37$ (Art. $\left.{ }^{\circ} 17\right)^{6}$ :

as coisas tombadas não poderão, em caso nenhum ser destruídas, demolidas ou mutiladas, nem, sem prévia autorização especial do Serviço do Patrimônio Histórico e Artístico Nacional, ser reparadas, pintadas ou restauradas, sob pena de multa de cincoenta por cento do dano causado.

Parágrafo único. Tratando-se de bens pertencentes à União, aos Estados ou aos municípios, a autoridade responsável pela infração do presente artigo incorrerá pessoalmente na multa.

A inobservância do dever de autorizar previamente intervenções ou a realização de danos podem ensejar a responsabilização administrativa, cível e criminal, cada uma com consequências jurídicas diferentes e aplicáveis simultaneamente. Por exemplo, o ato de demolir uma parede de imóvel tombado pode configurar ilícito administrativo, com a cobrança de multa, o dever de reparar (responsabilidade civil) e a prática de crime, tal como previsto no artigo 62 ou 63 da Lei $n^{\circ}$ 9605/98.

Destruir, inutilizar ou deteriorar:

I - bem especialmente protegido por lei, ato administrativo ou decisão judicial;

II - arquivo, registro, museu, biblioteca, pinacoteca, instalação científica ou similar protegido por lei, ato administrativo ou decisão judicial:

Pena - reclusão, de um a três anos, e multa.

Parágrafo único. Se o crime for culposo, a pena é de seis me-

ses a um ano de detenção, sem prejuízo da multa. (Art. ${ }^{\circ}$ 62)

Alterar o aspecto ou estrutura de edificação ou local especialmente protegido por lei, ato administrativo ou decisão judicial, em razão de seu valor paisagístico, ecológico, turístico, artístico, histórico, cultural, religioso, arqueológico, etnográfico ou monumental, sem autorização da autoridade competente ou em desacordo com a concedida: Pena - reclusão, de um a três anos, e multa. (Art. ${ }^{\circ}$ 63)

\footnotetext{
${ }^{6}$ Será adotada a redação original do Decreto-Lei $n^{\circ} 25 / 37$, com ortografia da época.
} 
Portanto, até mesmo para realizar a simples pintura do imóvel tombado é necessária a prévia autorização dos órgãos de preservação, sob pena de configuração de ilícitos civil, penal e administrativo.

As restrições em relação à pintura nem sempre são compreendidas e aceites pelos proprietários, que a consideram uma manifestação de sua individualidade e uma forma de valorização e cuidado com o imóvel. Além disso, pintar paredes como forma de expressão ${ }^{7}$ parece ser um impulso atávico, e algumas dessas marcas podem ser elementos identitários importantes e vestígios materiais fundamentais para entender culturas antigas e modernas.

Para refletir sobre o tema escolhido, vamos tomar como exemplo a questão do grafite e da pichação porque quando a Lei $n^{\circ} 9605 / 98$ foi promulgada ambos eram equiparados para fins de configuração de crime ambiental. Entretanto, a palavra "grafitar" foi retirada do artigo 66 da Lei $n^{\circ}$ 9605/98 através da Lei $n^{\circ} 12408 / 2011$ (Art. ${ }^{\circ} 65$ ), passando a ter a seguinte redação:

pichar ou por outro meio conspurcar edificação ou monumento urbano:

Pena - detenção, de 3 (três) meses a 1 (um) ano, e multa.

$\int 1^{\circ}-\mathrm{Se} o$ ato for realizado em monumento ou coisa tombada em virtude do seu valor artístico, arqueológico ou histórico, a pena é de 6 (seis) meses a 1 (um) ano de detenção e multa.

\2ㅇ Não constitui crime a prática de grafite realizada com o objetivo de valorizar o patrimônio público ou privado mediante manifestação artística, desde que consentida pelo proprietário e, quando couber, pelo locatário ou arrendatário do bem privado e, no caso de bem público, com a autorização do órgão competente e a observância das posturas municipais e das normas editadas pelos órgãos governamentais responsáveis pela preservação e conservação do patrimônio histórico e artístico nacional.

A distinção entre grafite e pichação, portanto, passou a ter relevância jurídica visto que a primeira forma de intervenção pode ser legalmente autorizada e a segunda não. Surge, então, a importante questão do que é considerado "grafite" para o Estado que - autoriza e para aqueles que o praticam, sendo evidente que nesta matéria não há consenso nem quanto à função social, nem quanto à forma, à temática e aos suportes que serão utilizados. Se para o pichador/grafiteiro são marcas distintivas, identitárias, formas de comunicação que consideram o suporte secundário e, como considera Baudrillard (1976, pp. 121-122), insurgências contra os signos da cidade humanizando-a e vivificando-a, para o Estado são o rompimento de uma estética urbana neutralizada e homogênea, estabelecida para os fins de reprodução da ordem e de uma economia representadas no espaço urbano.

A possibilidade legal de controlar essas expressões mediante prévia aprovação estatal aproxima o grafite da arte decorativa, que está intimamente associada à visão de

\footnotetext{
${ }_{7}$ Pinturas rupestres estão entre os mais importantes e antigos registros arqueológicos.
} 
cidade, de arte, e da forma e limites aceitáveis em função da estética urbana. Para tanto, e apenas do ponto de vista unilateral do Estado, podem ser adotados dois critérios de diferenciação preliminares entre a pichação e o grafite: a autorização (do proprietário e dos órgãos competentes) e o caráter artístico da intervenção.

Por esses critérios o grafite seria operacionalmente definido como a pintura artística precedida da autorização do proprietário/autoridade competente, enquanto a pichação seria a intervenção desautorizada, com ou sem valor artístico, definida por oposição. Essa caracterização, na prática, é intrínseca à atuação administrativa e se reflete nas normas que permitem o primeiro e proíbem o segundo.

A Portaria IPHAN n ${ }^{\circ} 420 / 2010$ estabelece o procedimento da autorização para realizar a "inserção de pinturas artísticas em muros e fachadas" tombados, estabelecendo como forma de reforma simplificada, que possibilita a análise do pedido sem a apresentação de um projeto, mas de uma mera descrição da intervenção, conforme dispõe o artigo $18, \int 2^{\circ}$.

Em tese, é legalmente possível a realização do grafite porém, se executado sem a prévia autorização do órgão de preservação ou diferente da concedida, pode ser considerado crime ambiental, independentemente do seu valor artístico. Além disso, a portaria não se refere, e nem admite, a possibilidade de utilizar outros materiais para a realização de obras de arte em fachadas e muros tombados, por exemplo, o revestimento com tecido ou colagem de materiais.

Já a pichação ou outras formas de "conspurcação" são percebidas como poluição, tal como definidas pelo artigo $3^{\circ}$ da Lei $n^{\circ} 6938 / 81$, pois podem representar uma forma de degradação da qualidade ambiental que direta ou indiretamente prejudique a saúde, a segurança e o bem-estar da população, crie condições adversas às atividades sociais e econômicas e/ou afete as condições estéticas ou sanitárias do meio ambiente.

A ideia de conspurcação observa o aspecto meramente estético da intervenção não autorizada do ponto de vista unilateral da administração pública, não havendo via de regra uma análise do valor comunicativo, que em certos contextos políticos não pode ser ignorado pelo poder público, nem do interesse público em sua manutenção. Essas marcas distintivas tatuadas no território contribuem para conferir identidade e podem ser percebidas como patrimônio cultural, ou serem negadas e apagadas quando consideradas uma violação ao padrão estético e como forma de poluição.

É bastante ilustrativo o caso do Município de São Paulo que, no âmbito de um programa denominado "Cidade Linda", promoveu dano aos grafites que compunham a estética urbana removendo-os sob o argumento que muitos deles estavam danificados e pichados ${ }^{8}$. Tal atitude motivou a propositura de duas ações populares contra o Município de São Paulo e o seu Prefeito (ações n 1004533-30.2017.8.26.0053 e 100396951.2017.8.26.0053), ambos condenados em 2019 ao pagamento de indenização fixada em $\mathrm{R} \$ 782.300,00$ (setecentos e oitenta e dois mil e trezentos reais) a ser revertida para o Fundo de Proteção do Patrimônio Cultural e Ambiental Paulistano (FUNCAP).

\footnotetext{
${ }^{8}$ Ver https://www.conjur.com.br/dl/doria-prefeitura-condenados-remocao.pdf
} 
A sentença ainda não é definitiva, podendo ser reformada pelo Tribunal de Justiça em grau recursal, mas já é um documento jurídico interessante pelo tipo de discussão que levanta, especialmente quanto à caracterização da arte urbana como patrimônio imaterial (forma de expressão) a ser protegida pelo poder público que, no caso, além da omissão do dever de conservá-los ainda praticou dano9.

Em que pese recusar um valor cultural ao grafite em si, visto que a sentença destaca a sua efemeridade e a ausência de pretensão ao tombamento, não existe uma impossibilidade jurídica em considerar determinada obra como passível de preservação específica, inclusive com atenção à sua materialidade. Nada impede que determinada pintura - classificada como grafite ou não - seja tombada, inclusive por valores diversos do artístico, como o histórico e paisagístico.

\section{REQUISITOS LEGAIS PARA A AUTORIZAÇÃo}

É o fator autorização que diferenciará a pichação do grafite para fins de configuração da sua licitude. Entretanto, se o valor artístico está na base da distinção entre o que é grafite e picho, a dúvida relevante, e preocupante considerando a tradição autoritária no Brasil, é se é possível discutir o mérito artístico, o tema da intervenção e, nos termos da Lei n $9605 / 98$, se a pintura "valorizou" o imóvel tombado.

A lei está repleta de conceitos indeterminados que deverão ser definidos tecnicamente em cada caso. A autorização prévia é importante porque previne a ocorrência de danos, e garante que o bem imóvel tombado (que é um bem cultural) prevaleça em relação à pintura, que é mero acessório.

Estabelecer parâmetros decisórios gerais que consigam proteger o imóvel tombado e, ao mesmo tempo, garantir a liberdade de manifestação artística através do grafite autorizado não é uma tarefa fácil. O conteúdo do ato de autorização pelas autoridades competentes deve visar a proteção do imóvel (suporte) e da estética urbana, estabelecendo condições para a forma de intervenção, o que será definido caso a caso, porém a partir de critérios gerais tais como sugerimos a partir das normas legais aplicáveis.

Quanto ao local de implantação: imóvel tombado, se isolado ou em conjunto, o lugar de construção de um monumento é um indicador da visão de mundo. Quando se transforma em um símbolo, é um repositório de significados os quais emergem das experiências profundas acumuladas ao longo do tempo (Tuan, 1980, p. 169).

Existe um porquê, um valor pelo qual o imóvel foi considerado bem cultural para fins de tombamento isolado ou em conjunto. Então, a sistemática da preservação legal do patrimônio cultural impõe que a análise da viabilidade de pintura artística em fachada ou muro deve tomar o próprio suporte como principal, sendo a obra de arte acessória e, por isso, secundária.

Segundo tal critério, inferido das normas legais aplicáveis, a autorização para realizar pinturas em imóveis tombados isoladamente será tendencialmente mais rigorosa do que para os que constam de um conjunto, sendo certo que em qualquer caso pode ser

\footnotetext{
${ }_{9}$ A sentença referida está disponível em https://www.conjur.com.br/dl/doria-prefeitura-condenados-remocao.pdf
} 
proibida se houver justificativa técnica, bem como deverá observar a situação do próprio suporte em relação ao conjunto tombado.

Quanto às características da obra, no caso da pintura artística, especialmente quanto às dimensões, escala relativa ao bem tombado e à forma de implantação no suporte e à cor ou paleta de cores.

Quanto ao material (espécies de tinta admissíveis), visto que a utilização de uma tinta inadequada pode causar dano, e tornar difícil ou excessivamente custosa a sua retirada.

Quanto ao tempo de permanência, pois o poder público deve condicionar a autorização à retirada da pintura. A questão da permanência vincula-se evidentemente à reversibilidade da intervenção, ou seja, dependendo do material utilizado, se será possível reverter o suporte ao estado anterior (status quo ante).

Quanto ao valor artístico, como destacado, o poder público deve evitar realizar juízos de qualidade sobre o mérito artístico da obra, sob pena de condicionar a eventual aprovação à subjetividade e às preferências de quem analisa o requerimento.

Entretanto, haverá situações-limite em que a pintura proposta pode prejudicar a leitura e a estética do monumento, configurando-se em uma desvalorização que justificaria a proibição em executá-la, desde que o respectivo ato administrativo seja devidamente motivado e fundado nas normas de preservação.

Quanto à temática da obra, o juízo administrativo sobre o conteúdo ou tema da obra pode ser tão problemático quanto a decisão sobre o seu valor artístico. Quando é encomendada ou patrocinada pelo poder público é claro que, na condição de contratante, pode estabelecer previamente sobre o que a obra de arte versará, mas não no exercício do poder de polícia administrativa.

A proposta da obra pode se revelar incompatível com a dignidade ou a aura do monumento, ou fazer referência a símbolos que são proibidos por lei, por exemplo, a veiculação da suástica como forma de apologia ao Nazismo, como estabelece a Lei $n^{\circ} 7716 / 89$, com a redação da Lei 9459/97 (Art. ${ }^{\circ}$ 20):

praticar, induzir ou incitar a discriminação ou preconceito de raça, cor, etnia, religião ou procedência nacional.

Pena: reclusão de um a três anos e multa.

$\int 1^{\circ}$ Fabricar, comercializar, distribuir ou veicular símbolos, emblemas, ornamentos, distintivos ou propaganda que utilizem a cruz suástica ou gamada, para fins de divulgação do nazismo.

Pena: reclusão de dois a cinco anos e multa.

Por força do princípio da legalidade, o poder público não poderia aprovar a utilização de imagens ilegais, ou que de qualquer forma danifiquem as edificações tombadas, portanto cabe-lhe também agir para retirá-las, adotando medidas administrativas e judiciais.

Os critérios gerais acima sugeridos para autorizar ou não uma pintura artística em bens tombados devem ser tecnicamente motivados, além de observar os princípios da proporcionalidade e da razoabilidade, conforme determina a Lei $n^{\circ}$ 9784/99. 
Finalmente, a Lei $n^{\circ} 9605 / 98$ considera que o grafite pode impactar positivamente a estética dos monumentos e assim contribuir para melhorar a vida das pessoas e dar identidade aos lugares. Há muitos exemplos de cidades que investiram no grafite como estratégia de embelezamento e identificação, como Valparaíso (Chile), que é um sítio considerado Patrimônio da Humanidade (Unesco, 2009, p. 696), e onde o grafite foi promovido por ações governamentais ${ }^{10}$.

As intervenções artísticas, por si mesmas, podem tornar-se bens culturais a serem preservados, dependendo da forma e da intensidade da apropriação e da afeição das pessoas. Portanto, quando se trata de grafite, a solução é casuística, e reside no equilíbrio entre o exercício do poder fiscalizatório do Estado para viabilizar a preservação e o direito individual à manifestação artística, e a sua compatibilização com o direito difuso à estética urbana, que deve ser disponível a todos, devendo ser por todos protegido (Santos, 2001, p. 943).

Quanto à posição relativa ao conjunto tombado, uma vez que a paisagem é um dos elementos ambientais a serem protegidos contra o impacto negativo das intervenções, inclusive considerando a eventual relação com outras pinturas e grafites já executados na área.

Embora seja evidente, mas por sua relevância deve ser citada para concluir a questão dos critérios construídos a partir da interpretação das normas legais, observa-se que a análise do projeto de grafite deve recair sobre a obra em si, não se levando em consideração os aspectos subjetivos em relação ao autor.

\section{O PROBLEMA DO ENTORNO}

O entorno é um perímetro de proteção da área ou imóvel tombado, ao qual não foi reconhecido um valor cultural específico, razão pela qual os imóveis nele situados não são considerados "especialmente protegidos por ato administrativo" para os fins de configuração de crime ambiental ou dano. Entretanto, apesar de não ser considerado espaço urbano protegido por esse ponto de vista, não significa que nele se pode fazer qualquer coisa, exatamente em razão de sua proximidade (vizinhança) e potencial interferência:

sem prévia autorização do Serviço do Patrimônio Histórico e Artístico Nacional, não se poderá, na vizinhança da coisa tombada, fazer construção que the impeça ou reduza a visibilidade, nem nela colocar anúncios ou cartazes, sob pena de ser mandada destruir a obra ou retirar o objéto, impondo-se nêste caso a multa de cincoenta por cento do valor do mesmo objéto. (Art. ${ }^{\circ} 18$ do Decreto-Lei $n^{\circ} 25 / 37$ )

O entorno ou vizinhança é a área envolvente do bem ou conjunto tombado cuja finalidade é proteger a visibilidade, e a sua delimitação é uma decisão que reflete uma

\footnotetext{
${ }^{10}$ Verhttps://www.cultura.gob.cl/eventos-actividades/el-arte-urbano-se-extiende-por-los-muros-de-la-region-de-valparaiso/.
} 
época específica, mas que abrange e ilustra temporalidades diferentes (Art. ${ }^{\circ} 18$ do Decreto-Lei $n^{\circ}$ 25/37). É formado por imóveis que foram sendo dispostos em um arranjo espacial tornado elemento de ambiência (Baudrillard, 2006, p. 37) como invólucro protetivo, mas também tem a função de prover informações sobre a natureza, o significado e a história do bem tombado (Motta \& Thompson, 2010, p. 22), ajudando a contar a história do lugar.

A proteção conferida pelo (não ao) entorno evoluiu tecnicamente para a proteção de outros valores além da visibilidade, como ambiência, harmonia, coerência, homogeneidade, escala e, em alguns casos até mesmo a compatibilidade e a respeitabilidade do monumento tombado (Motta \& Thompson, 2010, p. 35) ${ }^{11}$. Essa ampliação permitiu abranger outras hipóteses de violação que não estavam originalmente explícitas no Decreto-Lei n 25/37: "fazer construção que impeça ou reduza a visibilidade" ou "colocar anúncios ou cartazes" - consagrando-se o conceito amplo de visibilidade (compreensivo da ambiência), principalmente através de normas jurisprudenciais.

A visibilidade e a ambiência não se restringem ao aspecto físico mais imediato do bem tombado, e a sua violação refere-se a aspectos diretos como "a retirada da vista da coisa tombada, a modificação do ambiente circundante, a diferença de estilo arquitetônico, altimetria, volumetria, integração e emolduração", e tudo que afete a harmonia entre o bem e o contexto, como destaca Miranda (2014, p. 114), englobando também a criação de vazios através de demolição, que exigem a prévia manifestação do órgão de preservação (Miranda, 2014, p. 131). Os aspectos indiretos também podem configurar dano à visibilidade e ambiência, até mesmo uma maior evidência de um edifício, por exemplo, em razão de uma pintura chamativa, que faça desviar o foco do bem tombado ${ }^{12}$.

Aplicando essas ideias ao tema específico, conclui-se que a realização de grafites no entorno de áreas tombadas também exige a prévia autorização dos órgãos de preservação porque é possível que haja interferência negativa na visibilidade e na ambiência da área protegida. Os critérios são similares àqueles propostos para as áreas tombadas, porém menos rigorosos, e sem referência na manutenção da integridade do suporte: quanto à forma da pintura, especialmente quanto às dimensões, escala relativa ao bem ou conjunto tombado; quanto à cor ou paleta de cores, tempo de permanência, temática da obra e impacto ambiental.

Para a área de entorno valem as observações já realizadas para a área tombada quanto à necessidade de motivação técnica para a autorização ou não execução da pintura artística.

\footnotetext{
"Motta e Thompson (2010, p. 58) destacam que o IPHAN, em certo período da política de preservação, entendeu o entorno como "forma de preservação sem tombamento", que levou à ideia de tombamento de conjuntos.

${ }^{12}$ Confira-se o julgamento no Recurso Especial $n^{\circ}$ 1.127.633. Processo 2009/0136547-0, segunda turma do Superior Tribunal de Justiça.
} 


\section{BREVE ESTUdo DE CASO: UMA PINTURA ARTÍSTICA EM IMÓVEL TOMBADO NO BAIRRO DO RECIFE}

Não é frequente a solicitação para a realização de pinturas artísticas em imóveis tombados, e não há consenso técnico nos órgãos de preservação nem sobre a sua viabilidade e nem sobre os eventuais critérios para as autorizações. Conforme já explicitado nos itens anteriores, as leis de preservação brasileiras abrangem conceitos indeterminados que devem ser definidos tecnicamente pela análise específica e casuística, não obstante possam partir de conceitos gerais.

Para ilustrar um procedimento de autorização, foi analisado o processo administrativo $n^{\circ}$ 01498.000555/2018-15 $5^{13}$, que trata de solicitação para a realização de pintura artística em um imóvel integrante do conjunto tombado do Bairro do Recife, frente à Superintendência do IPHAN em Pernambuco.

A solicitação foi analisada através do Parecer Técnico $n^{\circ} 95 / 2018^{14}$, obtendo as seguintes conclusões e exigências:

- adotar um painel de fundo numa cor uniforme e neutra (concreto, bege, branco);

- preservar as bordas livres, mantendo $40 \%$ do fundo neutro sem pintura artística;

- se possível, tirar partido dos elementos existentes na fachada (exemplo: cercaduras em cantarias), na concepção artística.

Após a análise do esboço encaminhado, verifica-se que os desenhos propostos descolam das bordas e estão desconcentrados ao longo da fachada. Contudo, recomenda-se que o fundo neutro seja monocromático e sem texturas, servindo de pano de fundo para as imagens pintadas. Ressalta-se, ainda, que existem cercaduras em cantaria entaipadas na fachada lateral do imóvel que poderiam ser incorporadas à pintura artística, promovendo uma maior valorização das características arquitetônicas do imóvel.

O juízo administrativo neste caso levou em consideração os critérios relativos ao local de implantação (imóvel tombado no conjunto e sua situação específica) e às características da pintura (dimensões, escala relativa ao bem tombado, forma de implantação no suporte e cores).

Não houve manifestação explícita, neste caso, sobre o tipo de tinta admissível, tempo de permanência e nem quanto ao valor artístico ou temática da obra, embora o esboço das pinturas tenha sido submetido à análise do IPHAN, como se pode observar do processo administrativo $n^{\circ} 01498.000846 / 2018-03^{15}$.

\footnotetext{
${ }^{13} \mathrm{O}$ referido processo administrativo pode ser acessado através da consulta pública do sistema eletrônico de Informação do IPHAN (SEI IPHAN), mediante a informação do seu número, através do endereço https://sei.iphan.gov.br/sei/modulos/pesquisa/md_pesq_processo_pesquisar.php?acao_externa=protocolo_pesquisar\&acao_origem_externa=protocolo_ pesquisar\&id_orgao_acesso_externo=0

${ }^{14} \mathrm{O}$ referido processo administrativo pode ser acessado através da consulta pública do sistema eletrônico de Informação do IPHAN (SEI IPHAN), mediante a informação do seu número, através do endereço https://sei.iphan.gov.br/sei/modulos/pesquisa/md_pesq_processo_pesquisar.php?acao_externa=protocolo_pesquisar\&acao_origem_externa=protocolo_ pesquisar\&id_orgao_acesso_externo=0

${ }^{15} \mathrm{O}$ referido processo administrativo pode ser acessado através da consulta pública do sistema eletrônico de Informação do IPHAN (SEI IPHAN), mediante a informação do seu número, através do endereço https://sei.iphan.gov.br/sei/modulos/pesquisa/md_pesq_processo_pesquisar.php?acao_externa=protocolo_pesquisar\&acao_origem_externa=protocolo_ pesquisar\&id_orgao_acesso_externo $=0$
} 
O suporte para a execução foi o muro de um estacionamento, em uma rua estreita, portanto, o potencial de interferência da pintura no conjunto tombado foi minimizado, como se pode observar antes e depois da intervenção.

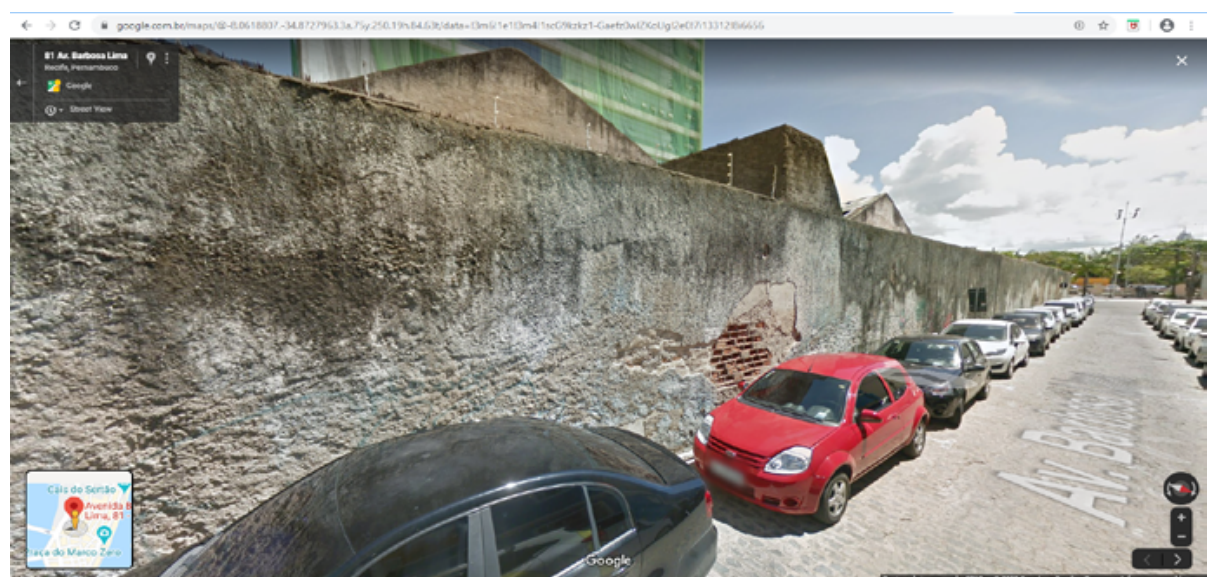

Figura 2: Rua Barbosa Lima, n. 81. Conjunto tombado do Bairro do Recife

Fonte: Google Maps (06/04/2020)

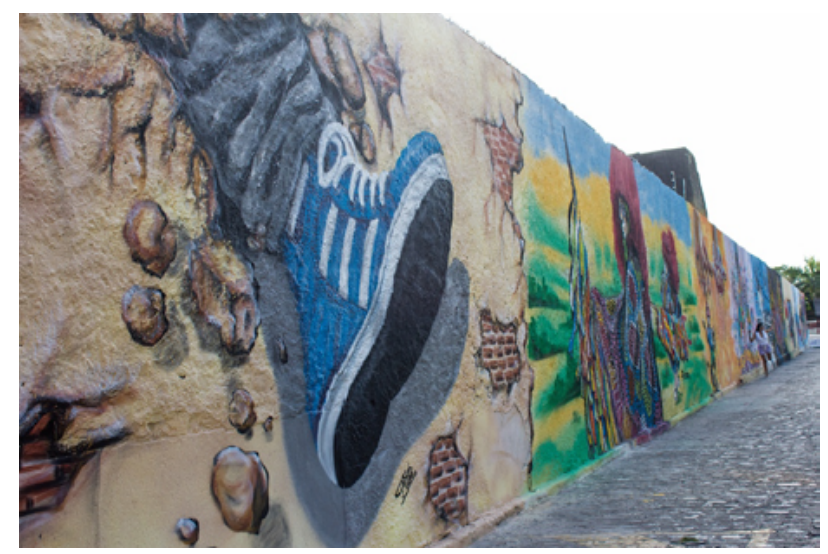

Figura 3: Rua Barbosa Lima, n. 81. Conjunto tombado do Bairro do Recife, após a intervenção $(9 / 9 / 2018)$. Detalhe com aproximação

Créditos: Fabiana Dantas

A temática das ilustrações é compatível com o caráter de bem cultural do conjunto tombado, não implicando nem desvalorização nem dano ao suporte, concluindo-se que a pintura citada atende em suas linhas gerais às recomendações do poder público. 


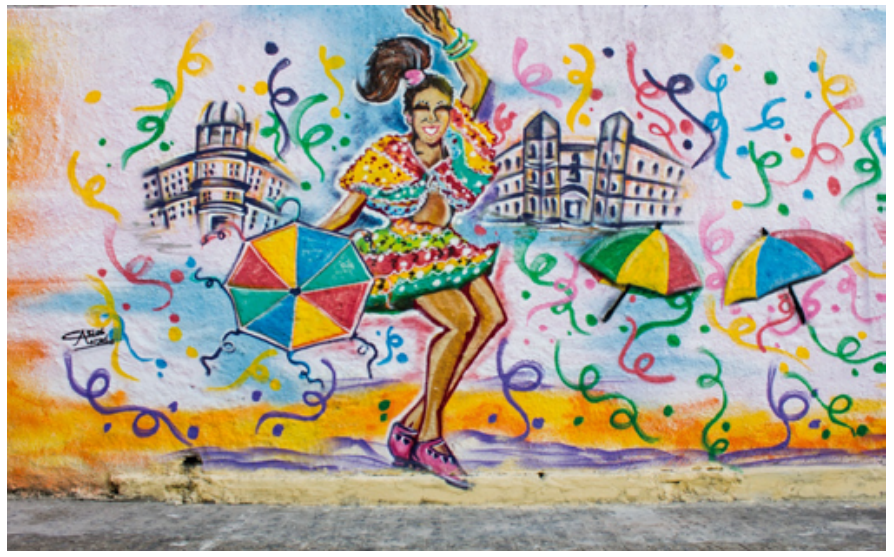

Figura 4: Rua Barbosa Lima, n. 81. Conjunto tombado do Bairro do Recife, após a intervenção (9/9/2018)

Créditos: Marcelo Müller

É importante destacar que a concessão da autorização prévia não exime o autor de ser responsabilizado caso a execute em desconformidade, e obriga as autoridades competentes a verificar a sua adequação mediante fiscalização posterior.

\section{Conclusão}

A legislação ambiental brasileira admite a execução de pinturas artísticas em imóveis tombados, desde que previamente autorizadas pelo proprietário e pelo poder público, e que configurem a melhoria da qualidade ambiental.

As análises realizadas pela administração pública para a concessão dessa autorização são discricionárias, baseadas em normas legais que possuem conceitos indeterminados, os quais serão aplicados conforme a visão de cidade, arte, comunicação, grafite, pichação, beleza vigentes na organização estatal, e em critérios técnicos que serão construídos por meio da prática administrativa.

Neste artigo buscou-se evidenciar alguns critérios técnicos inferidos da interpretação das leis de preservação do patrimônio cultural brasileiro e de sua aplicação, apontando como condições gerais para a execução do grafite em imóveis tombados os aspectos concretos do suporte material que irá sofrer a intervenção, bem como do seu contexto, com o objetivo de subsidiar a prática dos atos administrativos.

Como ilustração, foi realizado um breve estudo de caso de autorização de uma pintura artística em um imóvel tombado do Recife, onde foram destacados critérios relativos ao local de implantação (imóvel tombado no conjunto e sua situação específica) e às características da pintura (dimensões, escala relativa ao bem tombado, forma de implantação no suporte e cores).

Embora não tenha havido uma análise específica quanto ao mérito artístico das pinturas, nem à sua temática, percebe-se uma intenção de embelezamento e promoção de manifestações culturais locais que certamente influenciaram positivamente o juízo administrativo. As pinturas executadas talvez não correspondam ao conceito estabelecido 
de "grafite" na comunidade artística, e nem compartilhem da sua função contestatória originária, porém são assim consideradas para os fins de aplicação da legislação brasileira pela administração pública.

Em qualquer caso, vale destacar que a proteção do meio ambiente cultural é um dever de todos - poder público, sociedade e indivíduos - conforme estabelece o artigo 225 da Constituição Federal de 1988, e o objetivo de qualquer intervenção em um bem tombado deve garantir a sua conservação e valorização.

\section{REFERÊNCIAS}

Baudrillard, J. (1976). Kool killer ou l'insurrection par le signs In J. Baudrillard, L'echange symbolique et la mort (pp. 118-128). Paris: Gallimard.

Baudrillard, J. (2006). O sistema dos objetos. São Paulo: Perspectiva.

Constituição da República Federativa do Brasil, Art. 182.

Dantas, F. S. (2015). O patrimônio cultural protegido pelo Estado Brasileiro. In J. B. Campos, D. R. Preve \& I. F. Souza (Eds.), Patrimônio cultural, direito e meio ambiente: um debate sobre a globalização, cidadania e sustentabilidade (pp.31-54). Curitiba: Multideia.

Decreto-Lei ${ }^{\circ}$ 25/37, de 30 de novembro, República Federativa do Brasil.

Lei $n^{\circ} 6938 / 81$, de 31 de agosto, República Federativa do Brasil.

Lei n 9605/98, 12 de fevereiro, República Federativa do Brasil.

Lei nº 9985/2000, 18 de julho, República Federativa do Brasil.

Lei $n^{\circ} 16292 / 97$, de 29 de janeiro, Município de Recife.

Lei $n^{\circ}$ 14239/80, de 17 de dezembro, Município de Recife.

Leminski, P. (2013). Sol-te. In P. Leminski, Toda poesia. São Paulo: Companhia das Letras.

Miranda, M. P. de S. (2014). Lei do tombamento comentada: doutrina, jurisprudência e normas complementares. Belo Horizonte: Del Rey.

Motta, L. \& Thompson, A. (2010). Entorno de bens tombados. Rio de Janeiro: IPHAN.

Portaria $n^{\circ}$ 420/2010, de 22 de dezembro, Instituto do Patrimônio Histórico e Artístico Nacional.

Santos, A. S. R. (2001). Proteção jurídica da estética urbana. Boletim de Direito Administrativo, 11, 942-943.

Sanches, L. P. (2009). Paisagem e meio ambiente. In F. Ahmed \& R. Coutinho (Eds.), Patrimônio cultural e sua tutela jurídica (pp. 71-91). Rio de Janeiro: Lumen Juris.

Tuan, Y. (1980). Topofilia: um estudo da percepção, atitudes e valores do meio ambiente. São Paulo, Rio de Janeiro: Difel.

Unesco. (2009). El patrimônio de la Humanidade - descripciones y mapas de localización de los 878 sítios patrimônio da humanidade de la Unesco. Barcelona: Blume. 


\section{NOTA BIOGRÁFICA}

Fabiana Santos Dantas possui Doutorado em Direito pela Universidade Federal de Pernambuco (UFPE), instituição onde atua como docente do Centro de Ciências Jurídicas, e também exerce o cargo público de procuradora federal junto ao Instituto do Patrimônio Histórico e Artístico Nacional (IPHAN), em atividades de consultoria jurídica da Advocacia-Geral da União para a política federal de preservação de bens culturais.

ORCID: https://orcid.org/oooo-0001-6178-1566

Email: fabiana.dantas@ufpe.br

Morada: Centro de Ciências Jurídicas, Universidade Federal de Pernambuco (UFPE) Av. Prof. Moraes Rego, 1235, Cidade Universitária, Recife, PE, CEP: 50670-901

Submetido: 03/09/2019

Aceite: 28/11/2019 